\title{
Appropriate Medication Use in Individuals Aged 80 or More Years
}

\author{
Thierry Marquet, ${ }^{1}$ Catherine Deguines, ${ }^{2}$ Yves Juillet ${ }^{3}$ and the Participants in Round Table No. 5, \\ Giens $X X^{*}$ \\ 1 Laboratoires Lundbeck SAS, Paris, France \\ 2 Agence française de sécurité sanitaire des produits de santé (Afssaps), Saint-Denis, France \\ 3 Les Entreprises du Médicament, Paris, France
}

\begin{abstract}
Over the last few years, there has been a rapid and steadily expanding demographic explosion in the elderly population in France. When the most dynamic segment of this growth is considered, i.e. patients aged 80 years or more (who, moreover, usually have several diseases), under- or over-prescribing and/or inappropriate prescribing are identified. Three short- and medium-term recommendations are proposed: to quickly get expert consensus on the theme of prescribing for the aged patient; to integrate systematic drug re-evaluation into annual consultations for people aged 80 years or more; and to better coordinate actions and communication between institutions, health professionals and the pharmaceutical industry.
\end{abstract}

Keywords: appropriate medication use, drug, iatrogenesis, elderly

To complete the previous Giens 2003 Round Table project ${ }^{[1]}$ focusing on recommendations concerning drug re-evaluation for the elderly age group, two objectives have been identified by the 2004 Round Table members:

1. to identify indicators and tools favouring appropriate medication use for this age group;

2. to identify communication tools and ultimately induce behavioural changes favouring medication use.

\section{Context of Medication Consumption and Use in Elderly Patients in France}

\subsection{Frequency of Polymedication}

According to demographic data in France and the US, the elderly population in general and the population aged more than 80 years in particular are steadily growing.

In 1999, during the last census, people aged over 65 years accounted for more than 9400000 people in France, i.e. 15.7\% of the population. In 2004, this population had reached nearly ten million, i.e. $16.2 \%$ of the population according to the French national institute of statistics and economic studies (Institut National des Statistiques et des Etudes Economiques [INSEE]). ${ }^{[2]}$
The population aged over 80 years amounted to more than 2150 000 in 1999 and 2620000 in 2004, i.e. an increase of nearly $18 \%$.

Demographic data (INSEE 2003) confirm that this increase (absolute as well as relative) is likely to be sustained, as life expectancy at birth is growing (82.9 years) in women and (75.9 years) in men in France, while births are decreasing and reaching a no-replacement rate.

Drug consumption is high in the elderly population and would account for $33 \%$ of total drug consumption according to data from a French cohort study. ${ }^{[3]}$ Elderly individuals living in institutions consume more medicines than those living at home (5.2 vs 4.5 medicines per day). Drug consumption increases with patient age and, whatever the age, women consume more drugs than men. Thirty-seven percent of the cost of reimbursed medications is explained by prescriptions for elderly patients. ${ }^{[4]}$

The union of French government departments dealing with health insurance and sickness benefits in the Haute-Normandie region (L'Union Régionale des Caisses d'Assurance Maladie [URCAM] de Haute-Normandie) analysed the drug prescriptions for March 1999 for individuals aged more than 65 years. This study showed that, on average, 5.5 medicines were delivered per patient. In a study from the Bretagne region, URCAM focused

\footnotetext{
* For a list of participants, please see the end of the article.
} 
on people aged over 80 years and showed that, on average, 6.7 different medicines were delivered and reimbursed per patient.

A study by the Poitou-Charentes region URCAM focused on hospital admissions of people aged more than 70 years for 5 consecutive days. Drug consumption was, on average, five medicines per day, although it was higher in patients with adverse effects. The prevalence of adverse effects was $12.5 \%$.

In the Provence-Alpes-Côte d'Azur region, URCAM performed a study on polymedication in those aged 65 years and/or more, based upon a questionnaire given to patients selected according to medicine reimbursement criteria. This study showed that $28 \%$ of the patients had not complied with their treatment: $64 \%$ because they forgot, while in $70.5 \%$ noncompliance was intentional (feelings of satisfaction or dissatisfaction). Moreover, the study has shown that self-medication was occasional for $39 \%$ of the patients and usual for $25 \%$.

According to data originating from French government departments dealing with health insurance and sickness benefits in family medicine (MSA [Mutuelle Sociale Agricole], CNAMTS [Caisse Nationale d'Assurance Maladie des Travailleurs Salariés]), it appears that the therapeutic classes most prescribed in this age group are, in descending order, painkillers, cardiovascular drugs, digestive tract drugs and psychotropic drugs.

In summary, there is some evidence supporting polymedication in the very elderly patient because of the existence of comorbidities.

\subsection{Inappropriate Prescribing in the Elderly} fied:

Three main categories of prescribing misuse can be identi-

- underutilisation of useful medicines;

- over-prescribing of some drugs in the absence of any obvious indication, or drugs with an insufficient medical service level;

- inappropriate prescribing with, for example, failure to take into account known interactions, redundant treatments, noncompliance with dosages or treatment durations, failure to carry out or noncompliance with recommendations on the monitoring of treatment effects, with, overall, no regular reevaluation of the individual benefit/risk ratio or therapeutic strategy.

In the US, an expert panel consensus published a useful list of criteria to characterise inappropriate medication prescribing for people aged more than 65 years. ${ }^{[5]}$

The most iatrogenic drugs (i.e., most frequently causing adverse effects associated with hospitalisation) are, in descending order, anticoagulants (particularly anti-vitamin K), nonsteroidal anti-inflammatory drugs, diuretics, ACE (angiotensin-converting enzyme) inhibitors, $\beta$-blockers and antiarrhythmic agents, sulfamide drugs, hypoglycaemic agents, psychotropic drugs and anticholinergic drugs.

Faced with these observations, the general practitioners present have stressed how difficult it is to re-evaluate prescriptions, because their origin varies (e.g. specialists) and because patients become dependent on non-essential drugs that claim to improve their quality of life.

\subsection{The Risk}

Because of this population's fragility (homeostasis and metabolic impairment, renal insufficiency together with pharmacokinetic changes, and the direct influence of concomitant diseases), in people aged more than 65 years iatrogenesis has been reported to be responsible for $5-10 \%$ of total hospitalisations. ${ }^{[6]}$

Drug accidents are twice as frequent, on average, in those aged over 65 years and 10-20\% of these accidents lead to hospitalisation. A high proportion ( $>50 \%)$ of iatrogenesis in the elderly is deemed avoidable. [7]

While medicines are useful overall in patients aged more than 80 years, their appropriate use requires both some general and specific precautions, depending on the health of the individual patient. However, analysis of drug consumption in this population shows that both drug prescribing and utilisation are inappropriate.

\section{Indicators of and Tools to Identify Appropriate Medication Use}

The legal guideline for appropriate drug use consists of the Summary of Product Characteristics (SPC) and the patient leaflet.

Information referring to older individuals is available, even though disseminated over different SPC sections (4.1: therapeutic indications, 4.2: dosage and administration, 4.4: warnings and particular precautions for use, 5.2 pharmacokinetics properties), as imposed by the European Guideline (SPC Guideline, December 1999). ${ }^{[8]}$

The number of very elderly patients included in phase III trials is still insufficient, particularly for diseases that do not exclusively concern older patients, but in whom the drug treatments may be potentially useful. According to the International Conference on Harmonisation (ICH) Guideline dated 1994 (ICH Topic E7-Studies in Support of Special Populations: Geriatrics ${ }^{[9]}$ ): "Drugs must be studied in the different age groups, including older patients, when there is no doubt about usefulness. Patients 
included in clinical trials have to be representative of the population targeted by the treatment."[9]

Possible inclusion of the elderly population into the "ICH $\mathrm{E}_{2} \mathrm{E}$ pharmacovigilance planning"[10] could, in this respect, favour the optimisation of drug safety assessment before, and especially after, marketing authorisation is granted, taking into account this specific age group.

A specific pharmacovigilance assessment could be required in this age group.

Appropriate drug use, particularly in elderly people, requires 'Good Practice' recommendations to be taken into account. In this respect, it is also useful for the prescriber to consider the drug medical service level.

\section{In View of Drug Misuse in Individuals Aged 80 Years or More, What Are the Possible Intervention Strategies?}

In the elderly, individual interventions that encourage vigilance (in prescribers, pharmacists, patients'caregivers) must be distinguished from interventions at the population level: for this age group, a specific framework within the activities of the public health system is required.

\subsection{At the Individual Level}

\section{1.1 When Do We Need to Systematically Ask Whether Drug} Use in a Very Elderly Patient is Appropriate?

For an individual patient, the following alarm criteria may be evident:

- An aberrant prescription in terms of the number of products or an obvious risk of drug interactions.

- A concurrent event, e.g. a fall, an infectious episode or any unexpected deterioration in clinical symptoms and, a fortiori, when these events require hospitalisation. Hospitalisation should clearly be regarded as an opportunity to ensure that any drug treatment is appropriate and any recommendations should be specifically mentioned in the hospital reports that are forwarded to the consulting physicians.

- Any change that destabilises an elderly person, such as a bereavement, a move or admission to an institution, or a severe or harsh climate change.

- The appropriateness of any new prescription should be examined, taking into account existing prescriptions. This opportunity must be taken to fully review all current prescriptions, which are sometimes routinely renewed; their individual benefit/risk ratio, which may vary with time, should also be systematically reviewed.
- Computerised tools to assist with prescriptions may be useful, even though alarm signs need to be prioritised.

\subsubsection{How should Alterations in Individual Prescriptions be Managed?}

Therapeutic treatments should be prioritised, while symptomatic treatments that may improve the patient's quality of life should also be considered. Moreover, in the case of alterations in prescriptions, other prescribers, particularly specialists such as cardiologists should be consulted. Finally, for each intervention, the cooperation and compliance of the patient and that of his/her circle should be obtained.

The speedy establishment of consensus meetings of experts, and thus the development of recommendations, would be very useful (table I).

\subsection{At the Population Level}

3.2. 1 When and How to Act at the Population Level, and to Favour Appropriate Medication Use and a Collective Approach to the Prevention of latrogenesis

A systematic, annual re-evaluation of prescriptions for people aged 80 years and/or more should be included in the priorities of the implementation of Law No. 2004-806, August 9, 2004, ${ }^{[12]}$ relating to French public health policy. The objective of this law is to succeed within 5 years in reducing the frequency of drug-induced iatrogenic events occurring in ambulatory patients and leading to hospitalisation.

The content of these yearly medical consultations should be defined, as well as alarm criteria or conditions that may lead to a request for specialised advice from a geriatrician, as required by general practitioners.

The annual re-evaluation of prescriptions should thus be developed and raised to the status of an official 'Good Practice' recommendation.

Patient education represents an area for improvement with respect to the appropriate use of medication. It is necessary to give patients clear information in order to obtain their agreement on the therapeutic plan, to improve their compliance with treatment and to educate them with regard to warnings of iatrogenic events. Moreover, it would be desirable to promote educational programmes in the population aged 80 or more, targeted according to disease. Here also, it would be useful to establish expert recommendations. 
Table I. Practical questions that need to be asked when confronted with a prescription for a very elderly patient (reproduced from Doucet and Druesne, ${ }^{[11]}$ with permission)

The right questions

Before drafting the prescription: get information on the patient and his/her diseases

Which disease is covered and which pathologies are associated?

What are the patient's expectations?

What are the short- and medium-term therapeutic objectives?

Do we have the complete list of all the medicines currently consumed?

Is the patient able to take his medications by himself and follow the treatment surveillance plan?

When the prescription is drafted: master the treatment

Is the medication prescription really necessary?

What are the main pharmacokinetic parameters of the medicines under consideration?

Does the medicine have the best benefit/risk ratio for this individual?

Is it necessary to adapt this medicine ... and the dosages of any other medications?

Are the administration conditions suitable for the patient?

Is the prescription accurate, clear, legible and sufficiently comprehensible?

Have all the physicians involved in the care of the patient been informed?

How long does the treatment theoretically last?

What are the surveillance plan and procedures?

During the surveillance consultations: evaluate efficacy and safety Have the expected goals been achieved?

Has the initial information (somatic, cognitive status, as well as medications) changed?

Is the treatment still necessary?

Is a new symptom related to an unexpected adverse effect?

\section{Communicate and Induce Changes in Behaviour in Favour of Appropriate Medication Use}

The question we have specifically selected is as follows: which information on the appropriate use of medication is required to induce changes in behaviour?

A lack of consistency in the available information is still evident. Sources are numerous, the target audience of communications is too selective and means of communication are frequently limited.

Which targets and which approaches will ensure effective communication?

\subsection{Information Directed to Health Professionals}

General information, coordinated in short messages, clearly explained and appropriately timed should be favoured. An evaluation of the how well the messages are received by the target audience should be systematically performed.
The 'Charter of Quality' with respect to the medical visit the convention agreed between the 'Pharmaceutical Industry Syndicate' (LEEM; Les Entreprises du Médicament) and the 'Economic Committee of Health' (CEPS; Comité Economique des Produits de Santé ${ }^{[13]}$ - emphasises the important role of medical representatives in promoting appropriate drug use; the medical representative could contribute further by delivering systematic information on the pharmacological class of the medication, for example:

A proximity communication, the impact of which is often strong, should be equally favoured by means of the following:

- professional group meetings within the framework of continuous training, as well as information via the internet for physicians, pharmacists and nurses: pilot activities have already been initiated by the MSA in collaboration with a private group and are currently being evaluated;

- a hospitalisation report with an educational function integrated into educational activities.

Generally speaking, each time documents are drawn up that are likely to be distributed, in particular to health professionals, the way this information is presented should be specifically examined, as well as how to make it, as far as possible, acceptable to both health professionals and patients.

\subsection{Information Directed to Patients and their Circle}

- Such information must be clearly presented together with that aimed at professionals.

In October 2004, a vast programme 'Prevention of avoidable medicinal iatrogenesis in elderly patients' was developed in partnership with 'Santé en Action', the French professional associations, professional organisations and LEEM, ${ }^{[13]}$ and constitutes a good example of general public communication on that topic. Evaluation of the influence of this campaign on health professionals is planned, as should be the rule for any activity of this kind.

- By direct action in the newspapers most read by the target audience (e.g 'Notre Temps', 'Pleine Vie') and in audiovisuals.

From the point of view of a Round Table journalist: Elderly people receive multiple, most often contradictory, messages. As far as possible, we should try to provide them with clear and accurate information. We must give them some hope of being cured or that their pain will be alleviated, and explain to them any advances in medicine. Information conveyed by physicians, nursing staff, caregivers and the media should be consistent. We should realise that articles about people aged more than 80 years are not of great interest to chief editors. Regular releases in the 
media, to caregivers etc. of information, reports and practical recommendations would certainly be welcomed. General practitioners or geriatricians, not to forget the radio, TV, internet sites and DVD should be source of information for all.

\subsection{The Last but Not the Least Target of Information: the Media}

It would be necessary to sensitise journalists writing for the general public with respect to issues relating to the elderly, to convey to them the conviction that there are not that many issues dealing with the elderly that are taboo for this audience, and that the 'grey continent' is still to be conquered.

Finally, we should try to achieve as much partnership and cooperation as possible between institutions, health professionals and pharmaceutical companies.

\section{Conclusion}

Three converging recommendations stand out of the Round Table projects:

1. Rapidly obtain expert consensus on prescribing for people aged 80 years or more in terms of possible assistance in implementing health policies in 2005 .

2. Integrate systematic drug re-evaluation into the annual consultations dedicated to octogenarian patients. The content and procedures of these consultations should be based upon a clearly defined guideline.

3. Coordinate activities and communication between institutions, health insurance and sickness benefits, health professionals, the pharmaceutical industry and the media, in order to induce changes in the practice of health professionals, the behaviour of patients and the patients' environment, and to ensure that the information distributed is positively perceived by both professionals and patients. This could be achieved through a public organisation in charge of the above.

\section{Acknowledgements}

The authors thank Pr Jean Doucet and Dr Marine Jeantet for their involvement in finalisation of this article.

\section{Participants}

B. Boneu (CHU Purpan, Toulouse), S. Bonin-Guillaume (CHU Timone, Marseille), S. Bonnot-Marlier (Janssen Cilag, Issy-les-Moulineaux), C.-A. Cudennec (Chiesi SA, Courbevoie), R. Bordet (Pharmacologie, Lille), J.
Doucet (CHU, Rouen), L. Feldmann (Iris, Courbevoie), S. Goni (Lundbeck, Paris), M. Jeantet (CCMSA Direction Santé, Bagnolet), V. Lamarque (Baxter, Maurepas), H. Lelouet (Hôpital Henri Mondor, Créteil), S. Legrain (Hôpital Bichat, Paris), P. Maillière (Servier, Courbevoie), L. Merle (CHU Dupuytren, Limoges), M.-F. Padioleau (Paris, [journaliste]), S. Personnic (MG France, Paris), F. Piette (Hôpital Charles Foix, Ivry), P. Prévost (Direction Régionale du Service Médical, Rennes), O. Réveillaud (Bièvres, [Médecin de ville]), J.-R. Royer (Faculté de Médecine, Vandoeuvre-les-Nancy), J. Soletti (LEEM, Paris), J.-L. Vetel (Centre Hospitalier, Le Mans).

\section{References}

1. Fouchard M, Zannad F, et les participants à la Table Ronde $n^{\circ} 4$ de Giens XIX. Lecture critique, évaluation, valorisation, information sur les résultats des grands essais cliniques. Therapie 2004; 59 (3): 317-22

2. Institut National des Statistiques et des Etudes Economiques (INSEE) [online]. Available from URL: http://www.insee.fr [Accessed 2005 Jul 1]

3. Fourrier A, Dequae L, Chaslerie A, et al. Sociodemographic characteristics and polypharmacy in elderly people: data from the PAQUID Study. Post Market Surv 1993; 7: 291-8

4. Fenina A, Geffroy Y. Les comptes de la santé en 2000 : études et résultats $n^{\circ} 132$, 2001. Ministère de l'Emploi et de la Solidarité. Direction de la Recherche des Etudes de l'Evaluation et des Statistiques (DREES). Paris: DREES, 2001/08

5. Fick DM, Cooper JW, Wade WE, et al. Updating the Beers criteria for potentially inappropriate medication use in older adults: results of a US consensus panel of experts. Arch Intern Med 2003; 163 (22): 2716-24

6. Gonthier R, Cathebras $\mathrm{P}$, Delhomme M. Iatrogénèse médicamenteuse à l'origine d'une hospitalisation après 70 ans [abstract]. Rev Med Interne 1994; 15 Suppl. 3: 343

7. Doucet J, Jego A, Noel D, et al. Preventable and non-preventable risk factors for adverse drug events related to hospital admissions in the elderly. Clin Drug Invest 2002; 22 (6): 385-92

8. European Commission. A guideline on summary of product characteristics. 1999 Dec [online]. Available from URL: http://pharmacos.eudra.org/F2/eudralex/ vol-2/C/SPCGuidRev0-Dec99.pdf [Accessed 2005 Aug 15]

9. EMEA. ICH Topic E7. Studies in support of special populations: Geriatrics. Note for guidance on studies in support of special populations: geriatrics. CPMP/ICH/379/95. 1993 Sep [online]. Available from URL: http://www.emea. eu.int/pdfs/human/ich/037995en.pdf [Accessed 2005 Aug 15]

10. EMEA. ICH-E $\mathrm{E}_{2} \mathrm{E}$ pharmacovigilance planning. 2004 Dec 1 [online]. Available from URL: http://www.emea.eu.int/pdfs/human/ich/571603en.pdf [Accessed 2005 Aug 15]

11. Doucet J, Druesne L. Ordonnance du sujet âgé : les questions à se poser. La Revue du Praticien-Médecine Générale. Tome 17. N 624 du 29 septembre, 2003

12. Loi $\mathrm{n}^{\circ}$ 2004-806 du 9 août 2004 relative à la politique de santé publique et liens vers les décrets d'application [online]. Available from URL: http://www.legifrance.gouv.fr/html/actualite/actualite_legislative/decrets_application/2004-806 .htm [Accessed June 2005 Jun 27]

13. Les entreprises du médicament (LEEM) [online]. Available from URL: http://www.leem.org [Accessed 2005 Aug 15]

Correspondence and offprints: Thierry Marquet, Laboratoires LundbeckSAS, 37 avenue Pierre Ier de Serbie, Paris, 75008, France.

E-mail: thma@lundbeck.com 